\section{Public Health} Genomics
Public Health Genomics 2012;15:34-45

DOI: $\underline{10.1159 / 000328846}$
Received: September 4, 2010

Accepted after revision: April 18, 2011

Published online: July 2, 2011

\title{
Genetics in Health Care: An Overview of Current and Emerging Models
}

\author{
R.N. Battista ${ }^{a, b} \quad$ I. Blancquaert ${ }^{c} \quad$ A.-M. Laberge ${ }^{a, d} \quad$ N. van Schendel ${ }^{e} \quad$ N. Leduc ${ }^{b}$ \\ a Research Centre, CHU Sainte-Justine, ${ }^{b}$ Department of Health Administration, Faculty of Medicine, University of \\ Montreal, ' Department of Social and Preventive Medicine, University of Montreal, ${ }^{\mathrm{d}}$ Medical Genetics Division, \\ CHU Sainte-Justine, Department of Paediatrics, University of Montreal, and e Public Health Research Institute of the \\ University of Montreal (IRSPUM), Montreal, Que., Canada
}

\section{Key Words \\ Cancer genetics $\cdot$ Cardiogenetics $\cdot$ Clinical genetic services $\cdot$ Genomics $\cdot$ Health care delivery $\cdot$ Medical genetics $\cdot$ Neurogenetics $\cdot$ Primary health care $\cdot$ Professional roles $\cdot$ Service delivery models}

\begin{abstract}
Background: With advances in genetic and genomic medicine, the optimal integration of genetic services into the health care system remains of major concern in many countries. Objectives: To review the current organisation of genetic services, mostly in Europe, North America and Australia, explore emerging service delivery models, and probe challenges inherent in the transition process. Methods: We conducted a literature review of genetics in clinical practice: testing, diagnosis, counselling, and treatment. We examined the basic structures of genetic services, examples of integrated networks, and existing professional resources. We investigated services belonging traditionally in medical genetics as well as those developed for more common diseases. Results: Multidisciplinary specialist clinics and coordinated services appeared to be key to delivering proper care in rare genetic disorders. For oncogenetics, neurogenetics and cardiogenetics, interprofessional collaboration be-
\end{abstract}

tween geneticists and other specialists seemed to be favoured. On the other hand, there was also a tendency toward the integration of genetic services directly into primary care. Among the most pressing challenges was the morphing of paediatric care into adult care. Conclusion: The coordination of activities between professionals in first-, second-, and third-line medical care is a primary objective calling for the reconfiguration of professional roles and responsibilities. This entails the forging of new relationships as well as an enhanced sharing of expertise and genetic information, including information regarding services. Barriers to overcome include the redistribution of roles, sharing of data and databases, and the lack of preparedness of non-genetics professionals and of the health care system in general.

Copyright $\odot 2011$ S. Karger AG, Basel

\section{Introduction}

With advances in genetic and genomic research and the development of new technologies, questions continue to be raised regarding the potential impact of genetics and genomics on the health care system [1-3]. Changes are already occurring in the provision of genetic services and the redefinition of professional roles [4-8], with a strong

\section{KARGER \\ Fax +4161306 1234 \\ E-Mail karger@karger.ch}

www.karger.com (c) 2011 S. Karger AG, Basel

$1662-4246 / 12 / 0151-0034 \$ 38.00 / 0$

Accessible online at:

www.karger.com/phg
Renaldo Battista

Department of Health Administration, Faculty of Medicine

University of Montreal, 1420 boulevard du Mont-Royal

Montreal, QC H2V 4P3 (Canada)

Tel. +1 5143436111 ext. 1366, E-Mail renaldo.battista@ umontreal.ca 
tendency to favour the integration of genetic medicine into other specialties [9] and into primary care [10-15]. In fact, the UK [16], many states in the USA [17, 18], and some Canadian provinces such as Ontario [19] and Quebec [20] have developed plans for restructuring their genetic services. At this pivotal time, the present article will review the current situation and explore future directions. We will begin by a brief description of the overall organisation of genetic services in various countries, examining the basic units of service delivery (genetic centres) and how these are integrated into community health care networks. We will assess the core professional resources available at this time. We will then go on to explore emerging service delivery models, examining the recent shift from rare to common diseases, with the increasing interest in cancer genetics, neurogenetics and cardiogenetics, and the involvement of primary care. Finally, we will conclude with some of the challenges inherent in the transition process, such as the reconfiguration of professional roles and the barriers to overcome toward the integration of services into the existing health care system.

\section{Methodology}

We conducted a review of the literature from 1996 to December 2010 using PubMed, MEDLINE, EMBASE and ISI Web of Science databases as well as the Google and Google Scholar search engines. We searched for information combining delivery of genetic services and health care, i.e. various combinations of ('Genetic services' or 'Genetic counseling' or 'Genetics, medical' or 'Genetics' or 'Genetic services and models, organizational') and ('Health services' or 'Health care' or 'Primary health care' or 'Health services needs and demand' or 'Health services accessibility' or 'Delivery of health care, integrated' or 'Delivery of health care' or 'Comprehensive health care' or 'Care coordination'). We retained over 500 references and governmental or specialised websites that pertained to genetics in medical practice and the roles and responsibilities of health care professionals involved therein. Search results discussing prescriptions for genetic testing, diagnosis, counselling, and treatment of genetic diseases and anomalies were considered relevant, while those on laboratory services were considered only insofar as they pertained to the organisation or delivery of clinical care.

\section{Results}

The literature covered mainly Europe, North America and Australia. For some European countries, recent information was available, but for others, the information came from a 1997 review by the Concerted Action on Genetic Services in Europe [21], an evaluation still deemed valid for most of Europe [22]. For most Canadian provinces, as well as many American and Australian states, we were able to find recent data. Key points are summarized in table 1.

\section{Current Organisation of Genetic Services}

We examined basic units of genetic services, integrated structures, and core professional resources.

\section{(1) Basic Units}

Although the organisation of genetic services varied between and even within countries, the core facilities or basic units were similar across the various settings. They consisted of genetic centres most often developed within a university or hospital, generally offering both clinical and laboratory services.

In 1997, at least 3 of 31 European countries (UK, the Netherlands and Belgium) had regional genetic centres integrating clinical and laboratory services, nurses, psychologists, and social workers [21]. By 2007, there were 26 such centres in the UK, 9 in the Netherlands and 8 in Belgium [23]. Whereas in 1997, France had virtually no genetic centres offering combined clinical and laboratory services [24], by 2002, it was setting up regional centres in association with university teaching hospitals [25]. In 2007, France had 67 referral centres for rare diseases, 20 for cancer, and 48 multidisciplinary clinics for prenatal diagnosis [23]. Most combined molecular genetics, cytogenetics and counselling within the same establishment. In Italy, a national web-based survey conducted in 2007 revealed that the 278 responding medical genetics centres were located mainly in university or hospital settings and comprised 102 clinical service units, 171 cytogenetics labs and 217 molecular genetics labs [26]. According to the authors, this disproportionate number of structures showed a clear lack of harmonisation. Only $28 \%$ were certified according to quality standards [26].

In the USA, genetic centres were generally affiliated with academic medical centres offering multidisciplinary patient care clinics, laboratory services and research opportunities [27]. Other settings included hospitals and private individual or group practices such as health maintenance organisations $[28,29]$. There were also freestanding centres for prenatal diagnosis, communitybased support groups and specialised programs in nonhealth care institutions [30].

In Canada, genetic centres were primarily linked to academic settings. In British Columbia, the Department 
Table 1. Genetic services at a glance

Current organisation

Basic units - core facilities

Setting: genetic centres, mostly university/hospital-based in major urban centres

Services: clinical, laboratory, and research facilities

Integrated networks (e.g. UK, Italy, USA, Canada, Australia)

Community or specialised clinics integrated with major genetic centres

Hub-and-spoke structures: core facility (hub) provides support and expertise to peripheral units (spokes)

Core professional resources (e.g. Europe, USA, Canada, Australia)

Medical genetics

Genetic counselling

Emerging service delivery models

General service delivery models

Integration into the health care system (e.g. Donnai and Elles model)

From rare disorders to common disease

Rare disorders (e.g. tuberous sclerosis, haemophilia, cystic fibrosis, sickle cell disease)

- Dedicated multidisciplinary clinics

- Coordination and information-sharing with primary care

- Partnerships with families and support groups

Common diseases (e.g. cancer genetics, neurogenetics and cardiogenetics)

- Collaborative models involving multiple specialists, allied health professionals and community

- Multistep procedures or algorithms for risk assessment, testing, counselling, and care

Towards enhanced primary care

Pyramid versus horizontal model

Gatekeeper model

Enhanced primary care model

Challenges in the reorganisation of genetic services

Reconfiguring professional roles

New paradigms: multidisciplinary teams coordinated by adult specialists, as affected children live longer

Expansion of nurses' role: case coordination

Expansion of genetic counsellors' role: professional development and support for other professionals

Overcoming barriers to the integration of genetic services

Interprofessional and interorganisational communications

Professional development

Preparedness of health care system

Key concepts

Complementary models: multidisciplinary teams, integration into primary care

Changing landscape: from paediatric to adult care organisational models

Coordination of activities between 1st-, 2nd-, 3rd-line medical care

Reconfiguration of professional roles and responsibilities

Sharing of expertise, genetic information and databases

of Medical Genetics at the University of British Columbia administered the Provincial Medical Genetics Program [31]. In Alberta, the University of Alberta (in Edmonton) [32] and the University of Calgary [33] provided services to the northern and southern parts of the province, respectively. Five university teaching hospital centres offered genetic services in Quebec; and similarly in Ontario, major centres were university-based [34-38]. In the Maritimes, the Maritime Medical Genetic Service was lo- cated at the IWK Health Centre, affiliated with Dalhousie University in Halifax, Nova Scotia.

\section{(2) Integrated Networks}

In Europe, North America and Australia, major genetic centres often coordinated their services with a number of specialised or general genetics clinics located in the community, in both urban and rural areas. This type of network is generally referred to as a hub-and-spoke struc- 
ture, the core facility (hub) providing support and expertise to the peripheral units (spokes). For further explanation, let us look at the following examples of hub-andspoke structures.

In the UK, each regional genetic centre accepted referrals from clinics in district hospitals and community facilities, forming an integral part of the National Health Service [39]. Centres also had established links with speciality clinics, such as oncology, and extended their reach to primary care providers.

In Italy, each region was responsible for organising its own genetic services, in collaboration with Italy's health department. Some regions were further advanced in this respect than others. Liguria and Emilia-Romagna were the first to develop and implement strategic planning. Emilia-Romagna's well-integrated service structure had 6 laboratory centres for cyto- and molecular genetics with one clinical genetics centre coordinating the activities of 4 regional branches [40]. Family-based diagnostic services were integrated with community-based screening. All clinical genetics centres were required to follow established protocols linking laboratory and clinical services.

The United States had no nation-wide network, with the exception of the recently created Regional Genetic and Newborn Screening Service Collaboratives [41] for the coordination of screening programs. Each state managed its own services and system of centres and outreach/ speciality clinics. These often offered genetic services for a specific condition or cluster of conditions, e.g. Huntington disease clinic or muscular dystrophy clinic [27]. Wisconsin, for example, had 2 university centres or health maintenance organisations with comprehensive and integrated services (hubs), 7 affiliated outreach clinics (spokes) and several speciality clinics [17, 42]. Illinois counted over 20 academic medical centres or hospitals (hubs) offering prenatal or reproductive genetic services, as well as paediatric and adult services, including cancer genetics. An equivalent number of outreach clinics (spokes) were spread throughout the state, as were 39 local community service centres mainly responsible for implementing screening programs and following up on affected individuals [43].

In Canada, the Ontario genetics program was based, as in the UK, on a regional network of services spread throughout its jurisdiction. With 9 genetic centres offering both clinical and laboratory services, 10 outreach and 9 cancer genetics clinics, it was believed to be the most comprehensive and coordinated system in Canada [19]. Services included diagnosis, counselling, screening, pre-

Genetics in Health Care natal genetics, and metabolic genetics. With the exception of the West, where 2 Alberta centres $[32,33]$ and the British Columbia [44] centre had a network of outreach clinics in urban and rural areas, no other region in the country seemed to have such extensive networks in place.

In Australia, service provision varied from state to state [45]. Two government organisations - the Genetic Health Services Victoria [46] and the Genetic Services of Western Australia [47] - ensured coordination and delivery in their jurisdictions according to a hub-and-spoke structure. Though services were most often centralised in metropolitan, regional and rural clinics, multiple independent establishments existed, even to the extent of one mainland territory contracting services from another state [45]. Generally, clinical services included specialised genetic risk assessment (including familial cancers), counselling, diagnosis, and prenatal testing.

\section{(3) Core Professional Resources}

Professionals in clinical genetics were generally divided into 2 groups: professionals in genetics, e.g. genetic counsellors and medical geneticists (physicians), and other health care professionals increasingly using genetics in routine care. The latter group included general practitioners, specialists, nurses, psychologists, and social workers. While we will concern ourselves only with the former for the moment, the distinction varied by region [6, 48]. For instance, in Europe, Skirton [6] split out general practitioners as a separate entity and included genetically specialised allied health care professionals into the genetics category. In the USA, the 2008 Genetic Services Policy Project [48] included genetics nurses with professionals in clinical genetics.

In Europe, 22 of the 27 European Union countries now recognise genetics as a medical speciality. The UK did so in 1970, the Netherlands in 1987, Sweden 1991, Germany 1992, and France in 1995 [20, 49]. In countries yet without official recognition, e.g. Belgium, physicians with a genetics background were in charge of centres for the diagnosis and treatment of genetic diseases [23].

If in the UK the term genetic counsellor signified a non-physician with a nursing or master's degree, in many European countries, it was still used to denote 'anyone who offers genetic counselling' [6], even when that person was not generally employed as such. Among these regions at the time of the 1997 Concerted Action on Genetic Services in Europe survey were France, Spain, Germany, Latvia, the Russian Federation, Slovenia, and Turkey [50]. Official recognition of genetic counselling in France in 2004 has seen 75 members certified to date [51]. In 2003, 
England alone had 200 genetic counsellors [16], and as of 2010, the UK Association of Genetic Nurses and Counsellors had 300 certified members [52].

Genetics was recognised as a medical speciality in the USA in 1991 [53]. Approximately 2,500 individuals have received certification in one or more of the American Board of Medical Genetics categories of practice since 1982, including 1,500 clinical geneticists [54]. Genetic counselling has been recognised as a profession in the USA since the early 1980s, and it has flourished since the creation of the American Board of Genetic Counselling in 1993 [50]. By 2007, there were over 2,000 genetic counsellors represented by the National Society of Genetic Counselors and 30 accredited graduate training programs [55].

Canada recognised genetics as a medical speciality in 1986 [56]. Canada was among the first countries worldwide to develop standards of training and expertise, overseen by a newly minted Canadian College of Medical Genetics in 1976 [57]. In 2009, Canada counted 80 medical geneticists. Most were located in major centres (British Columbia, Alberta, Ontario, and Quebec). Four accredited genetic counselling programs were available at the master's level (2 in Quebec, 1 in Ontario and 1 in British Columbia), 3 of which were also accredited by the American Board of Genetic Counseling [58, 59]. By 2009, the Canadian Association of Genetic Counsellors had certified 250 genetic counsellors [56].

The Australasian Society of Genetic Counsellors had 131 certified members in 2002 [50].

One of the more serious problems highlighted was the lack of specialised staff (medical geneticists and genetic counsellors) $[22,42,43,60]$. The situation was particularly critical, according to Cooksey et al. [61], since 'the medical genetics workforce, as currently constituted and directed, does not appear sufficient to meet expected patient care for clinical genetics services for the next 5-15 years'. Factors that would need addressing include the scant proportion of physicians choosing medical genetics as their speciality, regardless of scientific advances made in the last decade.

\section{Emerging Service Delivery Models}

We found a single comprehensive model of the interplay between genetic centres and other health care institutions, which will be described below. However, a major issue in many countries was the coordination of genetic and non-genetic specialities and the optimal integration of genetic services into the health care system. Furthermore, advances in genetics have led a number of authors $[10,11,13,15,29,62-64]$ to speculate that growing demand must necessarily involve primary care. We will thus examine general models first, then explore specific services for various diseases, and finally assess enhanced primary care.

\section{(1) General Service Delivery Models}

Based on the UK experience, Donnai and Elles [39] proposed a model linking regional centres with primary and secondary services on the one hand, and with specialised care like cancer centres and other tertiary services on the other. Regional centres would thus be well positioned to coordinate services and resources throughout the health care system; they could, for instance, mobilise national expertise in their networks to develop public health policy or practice guidelines while also relying on the experience of user groups (patients and their families). Other authors in the USA and Australia [65, 66] have emphasised the importance of creating partnerships with support groups or services for people with genetic disorders, recognising the psychosocial and ethical implications of genetic predispositions and anomalies on patient and family.

\section{(2) From Rare Disorders to Common Disease}

We will briefly describe the services traditionally considered part of medical genetics and then move on to the emerging fields of oncogenetics, neurogenetics and cardiogenetics.

(a) Rare Disorders - Towards Better Coordination of Services

Despite our extensive experience in the treatment of rare single gene disorders, issues of consolidation and improvement continue to be raised, especially from the standpoint of the coordination of services. To illustrate the situation, we refer to 2 documents in the UK, admittedly at the forefront of organised genetic services. The Genetic Interest Group in 1999 examined 4 rare diseases - tuberous sclerosis, neurofibromatosis, familial hypercholesterolemia, and haemochromatosis - and determined that these 'will be a part of many doctors' professional practice ... For the patient affected ... the question is closely related to the question of who should or is able to take a broad clinical perspective on the patient's needs' [67]. The authors felt that the paediatrician or, for adults, the general practitioner or internist should be systematically included. The report further highlighted the 
need for specialised multidisciplinary clinics. The UK's many tuberous sclerosis clinics generally comprised geneticists, neurologists, psychiatrists, and nephrologists. The 3 neurofibromatosis clinics had a geneticist working alongside paediatric neurologists, endocrinologists and ophthalmologists. There was no such team effort for haemochromatosis, where specialist interventions remained limited and uncoordinated.

In the second document, this one on haemophilia, Ludlam et al. [68] stressed the benefits of improved coordination in the management of prenatal diagnosis and the clinical-laboratory interface, i.e. communications between pregnant women, obstetrics, laboratory, and family physician. Solid links were further recommended between haemophilia centres and regional genetic centres, especially through certified genetic counsellors specialised in haemophilia who could be called upon for consultation. For genetic counselling, they foresaw a multidisciplinary approach, with medical specialists and nurses sharing the task of communicating information.

While haemophilia and cystic fibrosis were typical of diseases treated in the USA with a disease-specific, multidisciplinary team approach, the management of sickle cell disease still relied on the primary care provider, with subspecialist referrals [69]. The progress achieved in diagnosing and treating cystic fibrosis, especially through specialist centres established in various countries [70], allows us to acknowledge the importance of multidisciplinary teams. Cystic fibrosis is now also included in neonatal screening programs in several countries, and genetic counselling and support for parents of children diagnosed at birth occupy an important place [71, 72]. Genetic services personnel and other health professionals were seen as collaborating effectively in initiating followup and support.

Other rare diseases are also in need of comprehensive, multidisciplinary care. In this regard, it is worth mentioning the existence in Canada of the Ocular Genetics Program [73], established in 1994 at the Hospital for Sick Children in Toronto. It comprises ophthalmologists, a clinical coordinator-ophthalmic assistant, genetic counsellor, and social worker.

In essence, multidisciplinary specialist clinics and coordinated services appear to be key to delivering proper care in rare genetic disorders. Partnerships with affected families are important as well.

(b) Cancer Genetics

Collaborative models linking genetic specialists with other medical practitioners, cancer clinics with counsel- ling services, or even community, secondary and tertiary care, have been proposed in Europe [74-76], USA [77] and Japan $[78,79]$. Multidisciplinary teams have been in place, either permanently or on demand, in 7 cancer genetics clinics of the UK, Netherlands, Belgium, France, Germany, Italy, and Israel [74] including gynaecologists, gastroenterologists, or surgeons, and, in some cases (UK, Belgium and Israel), psychologists and specialist oncology nurses. The roles assigned varied between countries, as did the type of liaison planned.

For predisposition to inherited cancers, the Swiss used a standard algorithm in their 8 regional centres, for genetic testing and counselling in presymptomatic individuals, including risk assessment and distribution of information [75]. According to the authors, the proposed collaborative approach had the advantage of ensuring the use of genetic testing as only one tool among others in the risk assessment process, avoiding inappropriate testing and misuse of information.

Based on a literature review, Robb [80] identified 4 types of cancer genetics service delivery models involved in risk assessment. Among the implementation challenges was the promotion of effective interprofessional dialogue and collaboration. In the UK, 7 pilot projects based on the so-called Kenilworth model were implemented and evaluated [76]. In all of them, cross-specialist models of care involved close interaction between community, secondary and tertiary care.

\section{(c) Neurogenetics and Cardiogenetics}

Neurogenetics and cardiogenetics were not addressed in the literature to the same extent as cancer genetics. The attention paid to cancer genetic services can be explained primarily by the mid-1990s discovery of genes associated with breast or colorectal cancer, which immediately led to a flurry of requests, not only for cancer patients but also for individuals genetically predisposed [74, 81]. Cardiogenetics and neurogenetics are expected to undergo similar growth over the next few years, particularly in the wake of the increasingly understood polygenic causes of several neurological disorders.

The only literature to our knowledge describing organised clinical neurogenetic services [82] emphasised the need for close involvement of other disciplines (neuropsychiatry, physiotherapy, speech therapy, etc.) in addition to 'crucial' collaboration among neurologists, clinical and laboratory geneticists, and nurse specialists. Stressing the importance of careful planning for the variety of procedures involved (diagnostic or presymptomatic tests, counselling), the authors envisioned neurolo- 
gists trained in neurogenetics. 'The previous model of neurologist as diagnostician and clinical geneticist as genetic counsellor does not give the patient and family the best service.'

Van Langen et al. [8], exploring the roles of cardiologists and geneticists in a survey conducted in the Netherlands for hypertrophic cardiomyopathy, observed that both groups wished to share rather than divide responsibilities. A 'shared collaborative model' at various stages of the intervention implied a partnership in communicating information on the hereditary nature of the disease, interpreting diagnostic tests and discussing these with the patient. In France, for presymptomatic or prenatal diagnosis, Charron et al. [83] suggested a multidisciplinary approach combined with a multi-step procedure: general information sessions, post-test follow-ups involving psychological support, and cardiological examinations with discussion of results. Throughout the intervention process, a cardiologist, geneticist and psychologist would work together to improve the quality of life of patient and family alike. Giving families information and support, as in the sudden death of a young individual, were key elements in the provision of cardiogenetic services, involving cardiologists, clinical geneticists, genetic counsellors, and forensic pathologists [84].

\section{(3) Towards Enhanced Primary Care}

The provision of genetic services through primary care is part of a tradition that Julian-Reynier et al. [85] called 'the pyramid model' to integrate the latest genetic science into all tiers of medical and paramedical practice, adding to the skills and role of the general practitioner [11] and paediatrician [86]. This contrasts with the horizontal model seen in France, which, at least until the late 1990 s, tended to view medical genetics as a new speciality reserved to medical geneticists.

Besides being the first contact with the health care system, primary care has 3 advantages that could enhance the effectiveness of genetic services provision: comprehensiveness, longitudinality (ongoing care) and coordination $[11,13,15,87]$. However, the 'primary-care gatekeeper model', a tradition firmly established in the UK, Netherlands, Denmark, and Spain, would delineate clinical genetics as a speciality for referral. This approach would fail to fully recognise the ever-increasing pace of medical genetics [11] and the resulting alteration in practice in every speciality, including primary care [43, 87]. Nevertheless, the primary-care gatekeeper model might be a first step favouring the gradual introduction of integrated genetic services.
Primary care could play a more significant role in the future, not only for adult services in diseases such as Huntington's, some cancers and other multifactorial disorders, but also for screening programs and prenatal diagnosis, encouraging concurrent discussion enabling informed choices [11, 13]. Emery and Hayflick [11], as well as other researchers [88-90], believe that pharmacogenetics also will end up finding a place in the primary-care setting.

In a 2005 study in Wales [10], primary care physicians were invited to propose additional service delivery models and rank them according to benefits and drawbacks. All agreed that the current gatekeeper model would not adequately fill the demand for genetic assessment, counselling and testing. They pictured genetic services as close to primary care, either in community settings or delivered by general/nurse practitioners with special skills in this area. The latter model was one of the most promising identified. This enhanced primary care model was defined as 'a service located within primary care, with specialists in genetic risk assessment, with support made possible by information technology and software applications'. Integration of certain genetic services into primary care would of course imply the need for an increase in material resources and professional skills.

\section{Challenges in the Reorganisation of Genetic Services}

While traditionally cared for by paediatric subspecialists, most children with cystic fibrosis, haemophilia and sickle cell disease now survive to adulthood, with the resultant need for continuing care. The transition from paediatric to adult care delivery and the implied reconfiguration of professional roles are among the most important challenges in the reorganisation of genetic services. Dominant problematics in reorganisation appear to be coordination and interprofessional collaboration, whether one is dealing with disease-specific models, enhanced primary care or any of the 3 main categories of clinical genetics: prenatal, paediatric and adult services.

\section{(1) Reconfiguring Professional Roles}

In the transition from traditional paediatric models to services adapted to the needs of adults with single-gene disorders (e.g. Huntington's disease, haemochromatosis, neurofibromatosis) or genetic predispositions to cancer or cardiovascular disease, Taylor et al. [7] concluded that new paradigms for genetic services had to extend beyond the paediatric model: a multidisciplinary team-based ap- 
proach was required, probably including an internist. Genetic counsellors, considered cornerstone [91] and key [39] to the integration of genetic services with primary care, would indeed be called upon to expand their involvement. In fact, specifically trained nurses should be capable of coordinating clinical services and establishing links with other health care resources. In the UK, these are known as genetic liaison nurses [92] and in the USA, genomic nurse case coordinators [93].

A number of studies have highlighted the role of genetic counsellors in the education and support of other professionals. In the USA, Cohen et al. [77] proposed a collaborative approach to cancer genetic testing, allowing for more effective use of genetic counsellors' expertise in the process of training and supervision of nurse practitioners in a community setting. Drury et al. [94] in the UK, Williamson and LeBlanc [95] in the USA, and Kromberg et al. [96] in Australia suggested a model that would require genetic counsellors to work with groups of general practitioners in primary care. This type of model would favour access to information for both physician and patient, ensuring more effective case management and follow-up. It would also permit the emergence of new roles and responsibilities for non-genetic professionals in primary and secondary care, such as specialists $[5,97,98]$. In addition to referring patients to genetics specialists, general practitioners could help identify at-risk cases, educate patients and recognise specific psychosocial needs [11]. For example, it is possible to offer, as part of primary care, genetic counselling services given by nurses with a special interest in genetics [99].

A survey in Canada by Bottorff et al. [5] of nurses and physicians (general practitioners and specialists) on their confidence and expectations in providing genetic services for adult-onset hereditary diseases showed that both groups saw themselves as playing important roles and being capable of sharing tasks with geneticists, nurses and physicians. In short, a variety of possible genetic service delivery models for adult onset hereditary diseases could be closely linked to the redefinition of professional roles and responsibilities, newly acquired competencies, and novel types of interrelationships.

Reorganisation of genetic services thus offers at least 2 challenges: (1) the redefinition and redistribution of roles and responsibilities in the context of an emerging paradigm for adult services requiring collaboration between professionals, and (2) the sharing of expertise between genetic professionals and others, e.g. between genetic counsellors and first-line physicians and nurses, with the resultant need for on-site training. Underlying these is the importance of coordination [100] and the identification of barriers to overcome.

\section{(2) Overcoming Barriers to the Integration of Genetic} Services

The barriers to the integration of genetic and genomic services into primary care are related to the following: (1) the nature of interprofessional and interorganisational communications, and (2) the inadequate professional development in the field of genetics and genomics in nongenetics professionals and the lack of preparedness of the health care system in general.

Professional boundaries represent a sizeable barrier. Commenting on the British experience, Martin et al. [12, $98,101]$ noted 3 types of resistance to policymakers' efforts: political, i.e. professional hierarchies protecting their own interests; cultural, i.e. lack of understanding with which to bridge the gap; and scientific, i.e. knowledge difficult to articulate and present to non-geneticists.

Indeed, at times, competing views are held by concurrent specialities. For instance, in the Canadian context, Miller et al. [102] found that in Ontario 'two communities offer parallel visions of cancer genetic care: one "genetic", the other "oncologic". Both communities argue from precedent that cancer genetics is a natural extension of their work: it is "what we do". Both communities also highlight the importance of their own expertise in providing core elements of cancer genetic care: it requires "what we know". Further, both communities perceive the need for leadership by their own (or a related) community as genetic medicine expands to include a broader array of more common and complex diseases: it is expanding "where we're leading".

The 2 visions differ not only in practice but also in the protocol of care determined by an agenda and coordination of professional roles singular to each. Which vision is the preferred one remains momentarily inarticulable, determined by distinctive 'communities of practice and discourse'.

As a corollary to political and cultural barriers, there is also the lack of training of non-genetic professionals, particularly the ones sought for integration into primary care networks. A serious problem in Europe [12,22] and the USA $[43,60]$ was the lack of awareness of genetics among non-genetic health care providers. Byck and Brennan [43] noted the need to generate professional interest, to offer continuing education, and to integrate genetic referral resources into current medical practice. These 
findings were reiterated in surveys of professional roles among physicians and nurses $[5,103]$ as well as of selfassessment among first-line professionals regarding their own knowledge and capacity for adequate referral [104108]. The 'self-assessed inadequacy of the primary care workforce was one of the largest obstacles to the integration of genomic services into medical practice', wrote Scheuner et al. [109] in a systematic revue on genomic medicine for common adult diseases like cardiovascular, diabetes and cancer. Deverka et al. [110], in a qualitative interview study of about 60 stakeholders in the American health care system, concurred, citing the fragmentation of the American health care system, its inability 'to efficiently utilize predictive risk information over an individual's lifetime' and its focus on disease care rather than prevention.

A number of steps remain to be taken before wellstructured genetic services can be fully integrated into primary health care [13]. These include implementation of resources adapted to new practice requirements, such as training programs for practitioners [94], information support systems, and so forth. Further, the integration of pharmacogenetics into primary care also requires resources, education and infrastructures [111].

\section{Conclusion}

Recent developments in genetics and genomics have rippled through the health care system, causing a reevaluation of the provision of genetic services. When we surveyed the distribution of these services in various countries for this review, 2 complementary types of service delivery models emerged, one favouring multidisciplinary teams comprised of genetic and non-genetic specialists, the other welcoming the integration of genetics and genomics into primary care. the most pressing, we found a changing landscape, where the paediatric care paradigm is morphing into adult care for genetic diseases previously encountered mostly in tion between professionals in genetics (physicians and genetic counsellors) and non-genetic health care professionals (specialist and general practitioners, nurses and social workers). between professionals in first-, second-, and third-line the reconfiguration of professional roles and responsibilities. This entails the forging of new relationships as well as an enhanced sharing of expertise and genetic information, including information regarding services. Barriers to overcome include the redistribution of roles and the sharing of data and databases. As seen above, political and cultural obstacles, including relationships between professional organisations as well as levels of genetic proficiency acquired by non-genetic professionals and the health care system, may impede the speed of changeover. Furthermore, genetic testing for susceptibility to common disorders is considered by some as a public health concern [112]. The role of public health institutions in the provision of individual health services varies between jurisdictions, but such institutions could play an important role in the widespread implementation of emerging delivery models through the development of relevant public health policies.

In conclusion, we feel that the concepts of sharing and the free circulation of genetic information among health care professionals and service structures need to be probed more deeply. Specifically, more research should be devoted to the clinical and functional integration of genetic and genomic medicine into the health care system.

\section{Acknowledgements}

The authors are grateful to Danielle Buch for the revision, rewrites, translation, and editing of the manuscript. Renaldo Battista holds the Canada Research Chair in Health Technology Assessment. Anne-Marie Laberge is supported by the Canadian Institutes of Health Research. Institutions involved in this study: University of Montreal and CHU Sainte-Justine.
Challenges were presented by the provision of genetics and genomics in health care systems, generally. Among childhood. Adult care models tended to favour collabora-

With this perspective, the coordination of activities medical care thus becomes a primary objective calling for

References
1 Calnan M, Wainwright D, Glasner P, New- bury-Ecob R, Ferlie E: Medicine's next gold- mine? The implications of new genetic health technologies for the health service. Med Health Care Philos 2006;9:33-41.
2 Finley Austin MJ, Kreiner T: Integrating ge- nomics technologies in health care: practice and policy challenges and opportunities. Physiol Genomics 2002;8:33-40.
3 Myers C, Paulk N, Dudlak C: Genomics: im- plications for health systems. Front Health Serv Manage 2001;17:3-16.
4 Benkendorf J, Cooksey J, Blitzer M, Lea D, Mansour J, Travers H, Saunders P, Gordon C: Transitions in genetics services delivery models (GSDM): Findings from case studies of four communities (abstract). 53rd ASHG Annu Meet, Los Angeles, November 2003.

Battista/Blancquaert/Laberge/ van Schendel/Leduc 
5 5 Bottorff JL, Blaine S, Carroll JC, Esplen MJ, Evans J, Nicolson Klimek ML, Meschino W, Ritvo P: The educational needs and professional roles of Canadian physicians and nurses regarding genetic testing and adult onset hereditary disease. Community Genet 2005;8:80-87.

6 Skirton H: Core competences in genetics for health professionals in Europe. Eurogentest, Unit 6.2 - professional perspectives. 2006. https://www.eshg.org/139.0.html.

7 Taylor MR, Edwards JG, Ku L: Lost in transition: challenges in the expanding field of adult genetics. Am J Med Genet C Semin Med Genet 2006;142C:294-303.

8 van Langen IM, Birnie E, Schuurman E, Tan HL, Hofman N, Bonsel GJ, Wilde AA: Preferences of cardiologists and clinical geneticists for the future organization of genetic care in hypertrophic cardiomyopathy: a survey. Clin Genet 2005;68:360-368.

9 Korf BR: Genetics in medical practice. Genet Med 2002;4(suppl 6):10S-14S.

$\checkmark 10$ Elwyn G, Edwards A, Iredale R, Davies P, Gray J: Identifying future models for delivering genetic services: a nominal group study in primary care. BMC Fam Pract 2005;6:14.

11 Emery J, Hayflick S: The challenge of integrating genetic medicine into primary care. Br Med J 2001;322:1027-1030.

-12 Martin G, Currie G, Finn R: Bringing genetics into primary care: findings from a national evaluation of pilots in England. J Health Serv Res Policy 2009; 14:204-211.

13 Qureshi N, Modell B, Modell M: Timeline: raising the profile of genetics in primary care. Nat Rev Genet 2004;5:783-790.

14 Robins R, Metcalfe S: Integrating genetics as practices of primary care. Soc Sci Med 2004; 59:223-233.

-15 Starfield B, Holtzman NA, Roland MO, Sibbald B, Harris R, Harris H: Primary care and genetic services. Health care in evolution. Eur J Public Health 2002;12:51-56.

16 Department of Health: Our Inheritance, Our Future: Realising the potential of genetics in the NHS. Genetics white paper presented to parliament by Secretary of State for Health, United Kingdom, June 2003.

17 Henry S, Pauli RM, Katcher ML: Genetic services plan for Wisconsin. WMJ 2005;104: 13-15.

18 King P, Rhoades ED: Oklahoma State Department of Health State Genetics Plan. J Okla State Med Assoc 2003;96:472-475.

19 Gouvernement de l'Ontario: Les services de génétique en Ontario: Cartographier l'avenir. Rapport du Comité consultatif de l'Ontario sur les nouvelles technologies génétiques prévisionnelles, 2001. http://www. geneticresourcesontario.ca.

20 Gouvernement du Québec: Ministère de la santé et des services sociaux. L'organisation des services génétiques au Québec: plan d'action 2005-2008. http://publications. msss.gouv.qc.ca/acrobat/f/documentation/2005/05-917-01.pdf.
21 Harris R, Reid M: Medical genetic services in 31 countries: an overview. Eur J Hum Genet 1997;5(suppl 2):3-21.

22 Lewis C: Developing European Quality Standards for Patient Information on Genetic Testing. Interim Report for Eurogenproject Unit 6.1. 2006. http://www.eurogentest. org/web/files/public/unit6/InterimReport. pdf.

23 Centre fédéral d'expertise des soins de santé (KCE): Organisation et financement du diagnostic génétique en Belgique. KCE reports vol. 65B, 2007. http://www.kce.fgov.be/index_fr.aspx?SGREF $=8945 \& \mathrm{CREF}=10046$.

24 Ayme S, Briard ML, Mattei JF: Genetic services in France. Eur J Hum Genet 1997;5 (suppl 2):76-80.

25 Aymé S, Lacombe D: Genetics in Europe (5): human Genetics in France. Newsletter no. 6. European Society of Human Genetics (ESHG), 2002. https://secure.medacad.org/ fileadmin/eshg/newsletter/06_April2002. pdf.

26 Dallapiccola B, Torrente I, Agolini E, Morena A, Mingarelli R: A nationwide genetic testing survey in Italy, year 2007. Genet Test Mol Biomarkers 2010;14:17-22.

27 Cooksey JA, Forte G, Benkendorf J, Blitzer MG: The medical genetics workforce: 2003 survey of ABMG certified geneticists. Genet Med 2005;7:439-443.

28 Bachman RP, Schoen EJ: Design and implementation of genetic services within an HMO. Manag Care Interface 1998;11:69-72.

29 Kinmonth AL, Reinhard J, Bobrow M, Pauker S: The new genetics. Implications for clinical services in Britain and the United States. BMJ 1998;316:767-770.

30 Cooksey JA: Genetic Service Providers Concepts and Findings Emerging from the Genetics Workforce Study. PowerPoint presentation Secretary's Advisory Committee on Genetics, Health and Society Washington DC, October 23, 2003.

31 UBC Medical Genetics Program. http:// www.medgen.ubc.ca/clin-genetics.htm.

32 Department of Medical Genetics at the University of Alberta. 2009. http://www.medicalgenetics.med.ualberta.ca/clinics/index. php.

33 University of Calgary Department of Medical Genetics. http://www.medicalgenetics. $\mathrm{ca} /$.

34 London Health Sciences Centre: Medical Genetics Program of Southwestern Ontario. http://www.lhsc.on.ca/About_Us/Genetics/.

35 Hamilton Health Sciences: Clinical Genetics Program. McMaster University Medical Centre. http://www.hamiltonhealthsciences.ca/body.cfm? xyzpdqabc $=0$ \&id $=11 \& a c-$ tion $=$ detail\&ref $=7$.

36 Toronto University Health Network: Adult Genetics Services. 2010. http://www.uhn.ca/ Clinics_\&_Services/services/adult_genetics/contact_us.asp.
37 Children's Hospital of Eastern Ontario (CHEO): Genetics. 2009. http://www.cheo. on.ca/En/genetics.

38 Genetic Resources Ontario. http://www.geneticresourcesontario.ca/general.htm.

-39 Donnai D, Elles R: Integrated regional genetic services: current and future provision. BMJ 2001;322:1048-1052.

40 Calzolari E, Baroncini A: International cooperation and networking in genetic health care provision: issues arising from the genetic services plan for the Emilia-Romagna region, Italy. Community Genet 2005;8:122129.

41 Puryear M, Weissman G, Watson M, Mann M, Strickland B, van Dyck PC: The regional genetic and newborn screening service collaboratives: the first two years. Ment Retard Dev Disabil Res Rev 2006;12:288-292.

42 Genetic Services Plan for Wisconsin. 2002. http://www.slh.wisc.edu/dotAsset/18714.pdf.

43 Byck GR, Brennan M: Illinois Genetic Services Needs Assessment. Chicago, Midwest Center for Health Workforce Studies, 2006.

44 BC Children's Hospital: Provincial Medical Genetics Program. 2010. http://www.bcchildrens.ca/Services/MedicalGenetics.

45 Metcalfe SA, Bittles AH, O’Leary P, Emery J: Australia: public health genomics. Public Health Genomics 2009;12:121-128.

46 Genetic Health Services Victoria. http:// www.genetichealthvic.net.au/Default. aspx?docid $=301 \mathrm{fc} 9 \mathrm{c} 2-4 \mathrm{c} 51-4752-897 \mathrm{a}$ 9a8b0166aaa4.

47 Genetic Services of Western Australia. http://www.kemh.health.wa.gov.au/services/genetics.

48 Genetic Services Policy Project: The delivery of genetic services in the United States (chapter 2). 2008. http://depts.washington.edu/ genpol/finalreport.

49 Joint UEMS/ESHG Clinical Genetics Workshop on Recognition and Education. January 2010. https://www.eshg.org/fileadmin/ www.eshg.org/documents/Europe/2010UE MSESHGRecognitionWorkshop.pdf.

50 Begleiter ML: Training for genetic counsellors. Nat Rev Genet 2002;3:557-561.

51 Association Française des Conseillers en Génétique. http://asso.orpha.net/AFCG/cgibin/.

52 Association of Genetic Nurses and Counsellors. http://www.agnc.org.uk/About\%20us/ aboutagnc.htm.

53 American Board of Medical Genetics. http:// www.abmg.org/pages/history.shtml.

54 American Board of Medical Genetics: Numbers of certified specialists in genetics. 2010 . http://www.abmg.org/pdf/Statistics $\% 20$ for $\% 20$ all $\% 20$ years $\% 20$ end $\% 20$ date $\% 20$ 2009.pdf.

55 American Board of Medical Genetics. http:// www.abmg.org/.

56 Little J, Potter B, Allanson J, Caulfield T, Carroll JC, Wilson B: Canada: public health genomics. Public Health Genomics 2009;12: 112-120. 
57 Leeming W: Tracing the shifting sands of 'medical genetics': what's in a name? Stud Hist Philos Biol Biomed Sci 2010;41:50-60.

58 The American Board of Genetic Counseling. 2010. http://www.abgc.net/ABGC/AmericanBoardofGeneticCounselors.asp.

59 The Canadian Association of Genetic Counsellors. 2006. http://www.cagc-accg.ca/content/view/66/85/.

60 Beene-Harris RY, Wang C, Bach JV: Barriers to access: results from focus groups to identify genetic service needs in the community. Community Genet 2007;10:10-18.

-61 Cooksey JA, Forte G, Benkendorf J, Blitzer MG: The state of the medical genetics workforce: findings of the 2003 survey of American Board of Medical Genetics certified geneticists. Genet Med 2005;7:439-443.

-62 Acheson LS, Wiesner GL: Current and future applications of genetics in primary care medicine. Prim Care 2004;31:449-460.

63 Christianson AL: Medical genetics in primary health care. Indian J Pediatr 2000;67:831835.

-64 Emery J, Watson E, Rose P, Andermann A: A systematic review of the literature exploring the role of primary care in genetic services. Fam Pract 1999;16:426-445.

-65 Barlow-Stewart KK, Gaff CL: Working in partnership with support services in the era of the new genetics. Med J Aust 2003;178: 515-519.

66 Cody JD: Creating partnerships and improving health care: the role of genetic advocacy groups. Genet Med 2006;8:797-799.

67 Genetic Interest Group: Achieving integrated services and support for families with rare genetic disorders. 1999. http://www.geneticalliance.org.uk/docs/gig_integrated.pdf.

-68 Ludlam CA, Pasi KJ, Bolton-Maggs P, Collins PW, Cumming AM, Dolan G, Fryer A, Harrington C, Hill FG, Peake IR, Perry DJ, Skirton H, Smith M; UK Haemophilia Centre Doctors' Organisation: A framework for genetic service provision for haemophilia and other inherited bleeding disorders. Haemophilia 2005;11:145-163.

-69 Grosse SD, Schechter MS, Kulkarni R, LloydPuryear MA, Strickland B, Trevathan E: Models of comprehensive multidisciplinary care for individuals in the United States with genetic disorders. Pediatrics 2009;123:407412.

-70 Roussey M, Desrues B, Turck D, Perez T, Wallaert B: Adult care centers for patients with cystic fibrosis: prerequisites and practical organization. Cystic Fibrosis Care Centers of Rennes and Lille (in French). Rev Mal Respir 2000;17:733-738.

-71 Collins V, Williamson R: Providing services for families with a genetic condition: a contrast between cystic fibrosis and Down syndrome. Pediatrics 2003;112:1177-1180.
Wheeler PG, Smith R, Dorkin H, Parad RB, Comeau AM, Bianchi DW: Genetic counseling after implementation of statewide cystic fibrosis newborn screening: two years' experience in one medical center. Genet Med 2001;3:411-415.

73 Morad Y, Sutherland J, DaSilva L, Ulster A, Shik J, Gallie B, Héon E, Levin AV: Ocular Genetics Program: multidisciplinary care of patients with ocular genetic eye disease. Can J Ophthalmol 2007;42:734-738.

74 Hopwood P, van Asperen CJ, Borreani G, Bourret P, Decruyenaere M, Dishon S, Eisinger F, Evans DG, Evers-Kiebooms G, Gangeri L, Hagoel L, Legius E, Nippert I, Rennert G, Schlegelberger B, Sevilla C, Sobol $\mathrm{H}$, Tibben A, Welkenhuysen M, JulianReynier C: Cancer genetics service provision: a comparison of seven European centres. Community Genet 2003;6:192-205.

75 Pichert G, Stahel, RA: Organizing cancer genetics programs: the Swiss model. J Clin Oncol 2000; 18(suppl 21):65S-69S.

-76 Eeles R, Purland G, Maher J, Evans DG: Delivering cancer genetics services - new ways of working. Fam Cancer 2007;6:163-167.

77 Cohen SA, McIlvried D, Schnieders J: A Collaborative approach to genetic testing: a community hospital's experience. J Genet Couns 2009; 18:530-533.

78 Fukushima Y, Sakurai A: Comprehensive genetics clinic for familial tumors: proposal for a suitable system in Japan. Int J Clin Oncol 2004;9:304-307.

-79 Takeda M, Ishida T, Ohnuki K, Suzuki A, Sakayori M, Ishioka C, Nomizu T, Noguchi S, Matsubara Y, Ohuchi N: Collaboration of breast cancer clinic and genetic counseling division for BRCA1 and BRCA2 mutation family in Japan. Breast Cancer 2004;11:30 32.

80 Robb L: Models of cancer genetic service delivery. PowerPoint presentation, APOGÉENet Seminar, Montreal, April 2007.

81 Epplein M, Koon KP, Ramsey SD, Potter JD: Genetic services for familial cancer patients: a follow-up survey of National Cancer Institute Cancer Centers. J Clin Oncol 2005;23: 4713-4718.

82 Hanna MG, Wood NW: Running a neurogenetic clinic. J Neurol Neurosurg Psychiatry 2002;73(suppl 2):II2-II4.

83 Charron P, Héron D, Gargiulo M, Richard P, Dubourg O, Desnos M, Bouhour JB, Feingold J, Carrier L, Hainque B, Schwartz K, Komajda M: Genetic testing and genetic counselling in hypertrophic cardiomyopathy: the French experience. J Med Genet 2002;39:741-746.

84 Ingles J, Semsarian C: Sudden cardiac death in the young: a clinical genetic approach. Intern Med J 2007;37:32-37.

-85 Julian-Reynier C, Moatti JP, Bourret P, Eisinger F, Sobol H: Vers une colonisation génétique de la médecine? Sociol Soc 1996;28: 141-155.
86 Cheng TL, Cohn RD, Dover, GJ: The genetics revolution and primary care pediatrics. JAMA 2008;299:451-453.

87 Greendale K, Pyeritz RE: Empowering primary care health professionals in medical genetics: how soon? How fast? How far? Am J Med Genet 2001;106:223-232.

88 Grice GR, Seaton TL, Woodland AM, McLeod HL: Defining the opportunity for pharmacogenetic intervention in primary care. Pharmacogenomics 2006;7:61-65.

89 Hopkins MM, Martin PA: Role of pharmacogenetics in the use of CNS drugs: from drug pipeline to primary care? Exp Rev Neurother 2006;6:1765-1767.

$\checkmark 90$ Robertson JA, Brody B, Buchanan A, Kahn J, McPherson E: Pharmacogenetic challenges for the health care system. Health Aff 2002;21:155-167.

-91 Agan N, Gregg AR: Elements of a genetics counseling service. Obstet Gynecol Clin North Am 2002;29:255-263.

-92 Shickle D, Hapgood R, Qureshi N: The genetics liaison nurse role as a means of educating and supporting primary care professionals. Fam Pract 2002;19:193-196.

$\$ 93$ Lea DH, Monsen MT: Preparing Nurses for a 21st century role in genomics-based health care. Nurs Educ Perspect 2003;24: $75-80$.

94 Drury N, Bethea J, Guilbert P, Qureshi N: Genetics support to primary care practitioners - a demonstration project. J Genet Couns 2007;16:583-591.

95 Williamson L, LeBlanc DB: A genetic services practice model: advanced practice nurse and genetic counsellor team. Newborn Infant Nurs Rev 2008;8:30-35.

96 Kromberg JG, Parkes J, Taylor S: Genetic counselling as a developing healthcare profession: a case study in the Queensland context. Aust J Prim Health 2006;12:33-39.

97 Bennett C, Burton H, Farndon P: Competences, education and support for new roles in cancer genetics services: outcomes from the cancer genetics pilot projects. Fam Cancer 2007;6:171-180.

98 Martin GP, Finn R, Currie G: National evaluation of NHS genetics service investments: emerging issues from the cancer genetics pilots. Fam Cancer 2007;6:257-263.

-99 Westwood G, Pickering RM, Latter S, Lucassen A, Little P, Karen Temple I: Feasibility and acceptability of providing nurse counsellor genetics clinics in primary care. J Adv Nurs 2006;53:591-604.

100 Shortell SM, Gillies RR, Anderson DA, Erickson KM, Mitchell JB: Remaking Health Care in America: The Evolution of Organized Delivery Systems, ed 2. San Francisco, Jossey-Bass, 2000. 
101 Martin G, Currie G, Finn R: Reconfiguring or reproducing intra-professional boundaries? Specialist expertise, generalist knowledge and the modernization of the medical workforce. Soc Sci Med 2009;68: 1191-1198.

102 Miller FA, Giacomini M, Ahern C: Contending visions in the evolution of genetic medicine: the case of cancer genetic services in Ontario, Canada. Soc Sci Med 2008; 67:152-160.

103 Bankhead C, Emery J, Qureshi N, Campbell H, Austoker J, Watson E: New developments in genetics - knowledge, attitudes and information needs of practice nurses. Fam Pract 2001;18:475-486.

104 Aalfs CM, Smets EM, de Haes HC, Leschot NJ: Referral for genetic counselling during pregnancy: limited alertness and awareness about genetic risk factors among GPs. Fam Pract 2003;20:135-141.
05 Guttmacher A, Poeteous ME, McInerney JD: Educating health-care professionals about genetics and genomics. Nat Rev 2007; 8:151-157.

106 Morgan S, McLeod D, Kidd A, Langford B: Genetic testing in New Zealand: the role of the general practitioner. N Z Med J 2004; 117:U1178.

107 McCann S, MacAuley D, Barnett Y: Genetic consultations in primary care: GPs' responses to three scenarios. Scand J Prim Health Care 2005;23:109-114.

108 Suther S, Goodson P: Barriers to the provision of genetic services by primary care physicians: a systematic review of the literature. Genet Med 2003;5:70-76.
109 Scheuner MT, Sieverding P, Shekelle PG: Delivery of genomic medicine for common chronic adult diseases: a systematic review. JAMA 2008;299:1320-1334.

110 Deverka PA, Doksum T, Carlson RJ: Integrating molecular medicine into the US health-care system: opportunities, barriers, and policy challenges. Clin Pharmacol Ther 2007;82:427-434.

111 Shields AE, Lerman C: Anticipating clinical integration of pharmacogenetic treatment strategies form addiction: are primary care physicians ready? Clin Pharmacol Ther 2008;83:635-639.

112 van El CG, Cornel MC; ESHG Public and Professional Policy Committee: Genetic testing and common disorders in a public health framework. Eur J Hum Genet 2011; 19:377-381. 